\title{
EL HIMNO A ENODIA EN EL ION DE EURÍPIDES
}

\author{
Hymn to Enodia in Euripides' Ion
}

\author{
Marcela Alejandra Ristorto* \\ UNR / CEHTRAC \\ mristor@gmail.com
}

\author{
Silvia Susana Reyes ${ }^{* *}$ \\ UNR / CEHTRAC \\ sisureyes@gmail.com
}

\section{Palabras clave \\ himnos trágicos; \\ Eurípides; \\ Enodia/Hécate}

\author{
Keywords \\ tragic hymns; \\ Euripides; \\ Enodia/Hecate
}

\section{Resumen}

E1 trabajo tiene como objetivo analizar la función que desempeña el himno a Enodia en el tercer estásimo de Ion (1048-1105), tanto en la trama como a nivel extraficcional. Se busca refutar las posturas críticas que a menudo han considerado que los cantos corales en la tragedia de Eurípides son poco relevantes para la acción desarrollada en escena. Desde una perspectiva diferente, se busca resaltar la relevancia que posee para la comprensión de Ion el himno a Enodia, diosa que aparentemente no tiene relación con el $\mu \tilde{v} \theta$ o $\varsigma$ de la tragedia, puesto que EnodiaHécate no se involucra con Erecteo ni con su descendencia. La oda coral, como

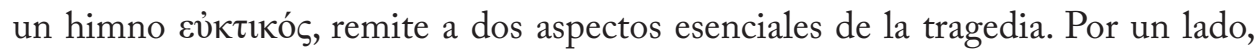
siendo Enodia protectora de los partos y de los niños recién nacidos, las peticiones del coro remiten a la supuesta realidad de Creúsa, a su carencia de un heredero para el trono de Atenas. Por otro lado, Enodia, como hija de Deméter, remite a los misterios eleusinos y órficos. Además, en este himno el coro describe los ritos eleusinos, lo que permite interpretarlo en relación con los cultos mistéricos. Cabe señalar que esta oda también puede ser considerada como una defixio, que busca perjudicar a Ion.

\begin{abstract}
Our paper aims to analyze the function the Hymn to Enodia performs in the third stasimon (1048-1105) of Euripides' Ion, within the plot as well as at the extrafictional level. Our purpose is also to refute the criticisms that have often considered the choral songs of Euripides to be not very relevant for the action developed on stage. From a different perspective, our intention is to highlight the relevance the hymn to Enodia - a goddess who apparently bears no relation to the tragedy's $\mu \tilde{v} \theta \mathrm{o}_{-}-$has for the understanding of Ion, since Enodia-Hecate is not

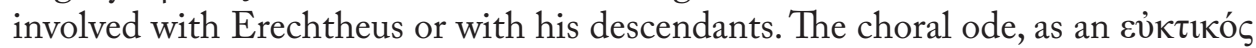
hymn, refers to two essential aspects of this tragedy. On the one hand, as Enodia is the protectress of deliveries and newborn children, the chorus' requests make reference to the supposed reality of Creusa, who has not yet given an heir to the throne of Athens. On the other hand, Enodia, as Demeter's daughter, alludes to Eleusinian and Orphic mysteries. Furthermore, in this hymn the chorus describes the Eleusinian rites, which makes it possible to interpret this hymn in relation to mystery cults. It should be noted that this ode can also be considered to be a defixio, which seeks to harm Ion.
\end{abstract}




\section{E1 himno a Enodia en el Ion de Eurípides}

El trabajo tiene como objetivo analizar la función que desempeña el himno a Enodia en el tercer estásimo de Ion $^{1}$ (1048-1105), tanto en la trama como a nivel extraficcional. Se busca refutar las posturas críticas que a menudo han considerado que los cantos corales en la tragedia de Eurípides son poco relevantes para la acción desarrollada en escena. Esta afirmación parece especialmente pertinente para este himno a Enodia, diosa que, aparentemente, no tiene relación con el $\mu \tilde{v} \theta$ o $\varsigma$ de la tragedia, puesto que no se involucra con Erecteo ni con su descendencia.

Si bien la fecha de performance de Ion es objeto de controversia, ${ }^{2}$ siguiendo la propuesta de Martin (2018, p. 24-25) es factible pensar que fue representada en el año 412, época en la que se cuestionaba el rol hegemónico de Atenas en la Hélade. En el imaginario ateniense esta supremacía estaba relacionada con su autoctonía, razón por la que era necesario que el linaje de Erecteo se perpetuase a través de Creúsa.

No solo debe tenerse en cuenta el aspecto político de la tragedia, sino también debe considerarse la relevancia que tiene la dimensión religiosa. La acción representada en Ion tiene lugar en Delfos y asume la forma del ritual de la theoria, a saber, la consulta al oráculo de Apolo. Por otro lado, la tragedia se inicia y finaliza con las rheseis de Hermes y de Atenea. Todos estos elementos evidencian que Ion no solo es una tragedia donde se problematiza lo político sino también la vida religiosa de la ciudad. ${ }^{3}$ Desde esta perspectiva, se busca resaltar la relevancia del himno a Enodia para la tragedia, ya que permite presentar una visión amplia de la religiosidad ateniense, la que no está limitada solo al culto a los Olímpicos sino que también incluye diversos cultos mistéricos.

\section{Enodia, ¿̨una única diosa o/y sincretismo religioso?}

Probablemente el nombre mismo Eivodía expresa la conexión de la diosa con los caminos y las encrucijadas, ya que su nombre deriva de los altares ubicados en las encrucijadas y en el frente de las

\footnotetext{
1. Una primera versión de este trabajo ha sido presentada en el $X X V^{\circ}$ Simposio Nacional de Estudios Clásicos y $I^{\circ}$ Congreso Internacional sobre el Mundo Clásico, desarrollados en Buenos Aires, del 31 de julio al 3 de agosto de 2018.

2. Cf. en la introducción a su edición de la tragedia, donde G. Martin (2018) analiza los debates acerca de la probable fecha de representación, teniendo en cuenta criterios métricos, estructurales y externos, a saber, las referencias o alusiones a hechos históricos. Cf. "On The Date of Euripides' Ion", G. Martin, CQ 60: 2, 2010, p. 647-651.

3. Los estudiosos suelen debatir acerca de las características y el rol de Apolo en esta tragedia (entre otros, ver Wassermann, 1940, Rosivach, 1977, Lloyd, 1986). Pero más allá del accionar de Febo como personaje, resulta relevante ver el cuestionamiento religioso en los himnos de la tragedia, los dos peanes a Apolo, a saber, las monodias de Ion (112-153) y de Creúsa (881-922) que presentan visiones encontradas del dios délfico. El himno a Atenea Níke (452-508) resalta las múltiples conexiones entre Atenas y Delfos, dado que las atenienses alaban a dioses venerados en ambas ciudades. Así a nivel extraficcional la oda permite reflexionar sobre el juego especular que hace el poeta, al presentar a Delfos, ámbito donde se desarrolla la acción, como una imagen idealizada de Atenas, ciudad donde debería reinar la armonía cívica (Markantonatos 2016, p. 209-228). Por su parte, como analizaremos en el presente trabajo, el himno a Enodia (10481105) permite reflexionar sobre la presencia de esta diosa en Atenas y su relación con los misterios de Eleusis y con los órficos.
} 
casas, siendo así su función el ser protectora de los lugares liminares y de pasaje. Por este motivo su culto público tenía que ver con la protección de las puertas de entrada a la ciudad. En el culto privado, Enodia se encargaba del cuidado y de la crianza de los niños, como lo testimonian dos inscripciones del siglo $\mathrm{V}$ encontradas en Larisa. ${ }^{4}$

Enodia es una de las deidades más importantes de Tesalia, ${ }^{5}$ venerada principalmente en Feras, donde tenía al menos dos templos. Su santuario más pretérito estaba situado fuera de la ciudad, cerca de la puerta norte y de una de las Necrópolis, en el camino hacia Larisa; la antigüedad del culto se comprueba por el hallazgo de exvotos que pueden fecharse en el siglo VIII a.C. y comienzos del siguiente. Otro lugar de culto dedicado a Enodia se encontraba cerca de otra de las Necrópolis de Feras, donde estaba asociada con Deméter y Zeus Meilichios. El culto de la diosa debió extenderse no solo por toda Tesalia a partir del siglo V a.C., sino también a Atenas. Se trata de lo que Allan (2004, p. 116) denomina: “internal syncretism', which involves the transfer of powers, characteristics, and divine epithets within a specific religious domain”. Así la diosa tesalia en Atenas, Enodia, es asimilada a Ártemis, a Perséfone y a Hécate, ${ }^{6}$ y termina por convertirse en un simple epíteto de estas diosas.

\section{Himno a Enodia (vv. 1048-1105) ${ }^{7}$}

Este himno constituye una petición de ayuda para que la diosa guíe el camino del anciano servidor que deberá ejecutar el plan de Creúsa para asesinar a Ion. Es decir, se invoca a una deidad vinculada al mundo subterráneo para perjudicar a una persona, razón por la cual este himno puede ser considerado una defixio (Mikalson, 1989, p. 84-5; Furley-Bremer, 2001, p. 329), es decir, un "hechizo vinculante" que tenía como finalidad atacar preventivamente a un enemigo peligroso (Faraone, 1991, p. 3). Martin (2019 ad loc) sostiene que este himno podría ser considerado una "plegaria por justicia", es decir, podría pertenecer al tipo de las maldiciones privadas contra los malhechores. Creúsa siente que ha sufrido una injusticia y sabe que no puede recurrir a ninguna autoridad para ser compensada. Su situación límite hace que exista una única autoridad a su disposición: la diosa de la magia y de la hechicería (Versnel, 1991, p. 68 y ss.; Gager, 1992, p. 175-180). Puede verse así que las mujeres del coro invocan a la diosa con un lenguaje fuerte y emotivo para apoyar la magia del veneno de Creúsa y

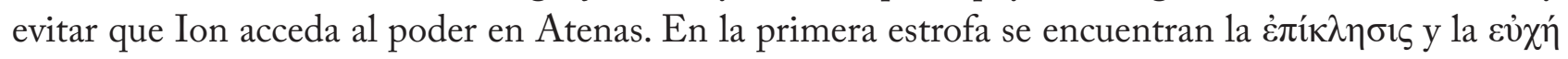
del himno (1048-1060):

4. $I G$ IX $2575,577$.

5. Cf. Milli, 2015, p. 147-158; Serafini, 2015.

6. Damos algunos ejemplos poéticos de esta vinculación entre las diosas: Enodia-Ártemis en Hes. Cat. fr. 26 M.-W; Enodia-Perséfone: en el OF 309; Enodia-Hécate en S. Fr. 535 R, en Call. Fr. 466 Pf.

7. El estásimo está compuesto por dos pares estróficos; algunos filólogos sostienen que solo la primera estrofa constituye un himno (Furley-Bremer, 2001, p. 328), mientras que otros afirman que analizan el primer par estrófico como una composición hímnica (Mantziou, 1981, p. 169 y ss.). En este trabajo consideramos que toda la oda puede ser pensada como un himno. Para el texto griego se sigue la edición de Martin (2018); las traducciones son nuestras. 


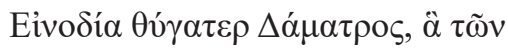

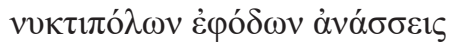

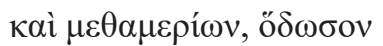

1050

$\delta v \sigma \theta \alpha v \alpha ́ \tau \omega v \kappa \rho \alpha \tau \eta ́ \rho \omega v \pi \lambda \eta-$

$\rho \omega ́ \mu \alpha \tau$ ' $\dot{\varepsilon} \varphi$ ' oĩol $\pi \dot{\varepsilon} \mu \pi \varepsilon 1$

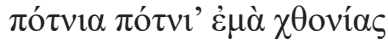

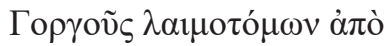

$\sigma \tau \alpha \lambda \alpha \gamma \mu \tilde{\omega} v$

1055

$\tau \tilde{\omega} \tau \tilde{\omega} v^{\prime}{ }^{\prime} \rho \rho \varepsilon \chi \theta \varepsilon i \delta \delta \tilde{\alpha} v$

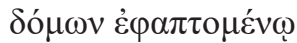

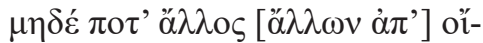

$\kappa \omega v \pi$ ód $\varepsilon \omega \varsigma \dot{\alpha} v \alpha ́ \sigma \sigma o 1$

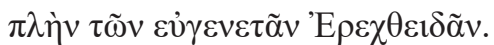

1060

Enodia, hija de Deméter, tú que gobiernas los caminos nocturnos, encamina también de día lo que colma la mortífera cratera contra quienes mi señora, mi señora lo envía, tomado de las gotas de sangre emanadas del cuello cortado de Gorgona que brotó de la tierra, contra quien se apodere de la casa de los Erecteidas. ¡Que nunca nadie procedente de otra familia gobierne mi ciudad, salvo los Erecteidas de noble nacimiento!

Se invoca el nombre de la diosa, indicando además su genealogía y la función que desempeña (1048-1050); luego se explicita la petición, que está vinculada a una actividad característica de la diosa no mencionada antes, a saber, la preparación y el empleo de pócimas funestas y, en este caso en particular, necesarias para acabar con quien se considera una amenaza para los Erecteidas. Es importante señalar que Hécate era una de las diosas más invocadas en las tablillas de maldición y en las "plegarias por justicia".

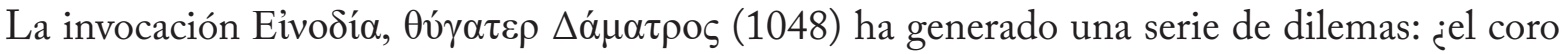
está conjurando a Enodia, la diosa tesalia, o a Hécate o a Perséfone? Eỉvodía debe considerarse una epíclesis de Hécate, ${ }^{8}$ cuando en el siglo $\mathrm{V}$, en Atenas, la diosa, en un lento y gradual proceso, adquiere nuevas prerrogativas conectadas con la esfera de la oscuridad y de la magia, es decir, un perfil "ctónico" (cf. Serafini,2015, p.114-115). La denominación a partir de la genealogía, "hija de Deméter", parecería indicar que el coro apela a Perséfone, dado que en la tradición religiosa griega Hécate y Perséfone no solo estaban relacionadas cultualmente en Eleusis sino que también habían sufrido un proceso de identificación (cf. Burian, 2009, ad loc.). ${ }^{9}$ No obstante, puede pensarse que el poeta juega con esta ambigüedad, ya que con esta ambigua invocación a Enodia-Hécate-Perséfone el coro apela al lado oscuro, misterioso y hostil de la deidad, invocándola en calidad de experta en venenos mortales (cf. Mikalson, 1989, p. 84). La posible identificación con Perséfone aludiría a la función de esta diosa como señora del Hades, y en cierto punto, anticipa su rol en los misterios eleusinos.

$\mathrm{Su}$ dominio sobre los caminos se expresa con el verbo ávó $\sigma \sigma \omega$ (1049), que usualmente se emplea para referirse a la autoridad de los tres hijos de Cronos (por ej., Il.XV 188), con el objetivo de

8. Eivodía como epíteto de Hécate aparece en S. $f r .492 \mathrm{~N}^{2}$ de Sófocles, y en el OH1, OF 309.

9. Sin embargo, en la tradición órfica, se consideraba que Deméter era la madre de Hécate (OF 219; 260). 
enfatizar el poder de la diosa. Además, este verbo resalta la importancia de Enodia-Hécate por su rol de mediadora entre la vida y la muerte, entre los dioses y los mortales, rol ya atestiguado en el Himno Homérico a Deméter (Zografou, 2010, p. 14).

Enodia-Hécate es una deidad ambigua, una amenaza contra la cual hay que protegerse con rituales profilácticos y, al mismo tiempo, es una diosa protectora que garantiza su auxilio a los mortales. Se ha traducido غ̇ $\varphi$ ó $\omega \omega v$ como "caminos", puesto que tanto Enodia como Hécate son diosas de las encrucijadas, de los caminos, los que eran considerados lugares liminares (que implican tanto fronteras como lugares de pasaje) peligrosos, por su dimensión de extranjeridad (cf. Serafini 2015, p. 112). Sin

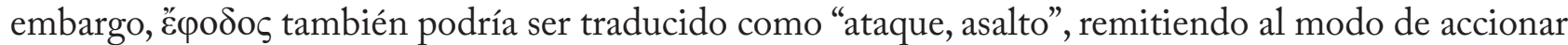
de deidades infernales tales como las Erinias (cf. A. Eu.375; cf. Furley-Bremer, 2001, ad loc.).

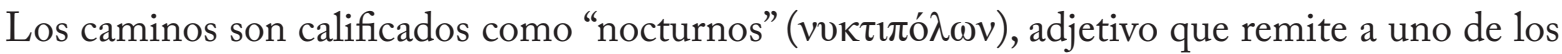

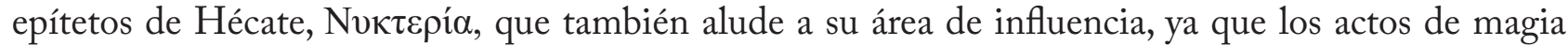
generalmente se ejecutaban de noche, ${ }^{10} \mathrm{y}$ de igual modo, los ritos en honor a estas diosas se celebraban de noche. ${ }^{11}$

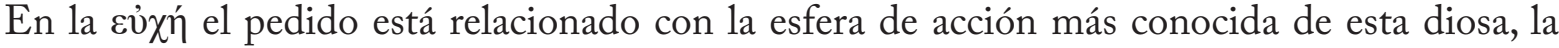
magia, las pócimas fatales (1050-5). Sin embargo, las servidoras de Creúsa se refieren eufemísticamente al veneno, ya que mencionan "lo que colma la mortífera cratera" ( $\delta v \sigma \theta \alpha v \alpha ́ \tau \omega \nu \kappa \rho \alpha \tau \eta ́ \rho \omega \nu \pi \lambda \eta \rho \omega ́ \mu \alpha \tau$ ', 1050-1). Vemos que este himno puede considerarse una defixio o una "plegaria por justicia", dado que las mujeres atenienses solicitan la aniquilación del supuesto hijo de Juto. Esta petición se expresa por medio del empleo del adjetivo, cuyo significado se halla vinculado al verbo $\delta v \sigma \theta \alpha v \alpha \tau \alpha ́ \omega$, indicando así "que trae una muerte cruel a Ion, gracias a la sangre de la Gorgona". ${ }^{12}$

La naturaleza de este veneno había sido explicitada por Creúsa en los vv. 1001 y ss., cuando expone al Anciano sus planes para librarse de Ion: Atenea había dado a Erictonio dos gotas de la sangre de la Gorgona en una cadena de oro, ${ }^{13}$ una mortífera y la otra salvífica. Sin embargo, el auditorio, familiarizado con las tablillas de maldición, recordaría que Гopүó era una deidad invocada junto a Hécate y a Perséfone, y aquí este canto opera como una suerte de maldición, ya que se desea la destrucción del joven.

En los versos 1058-9 el coro expresa claramente la estrecha vinculación del destino de Creúsa y su familia con el porvenir de Atenas. Es decir, el problema ya no concierne solamente a un oĩkos

10. Los rituales mágicos se realizaban preferentemente de noche, debido tanto a la naturaleza de las deidades involucradas como a los lugares donde se ejecutaban, tales como cementerios, encrucijadas, etc., cf. Versnel, 2002, p. 105-158, entre otros. 11. También en un tratado médico del siglo IV, Hp. Morb. Sacr. 1 relaciona Hécate-Enodia con situaciones anormales. Así, los magos y góetes atribuyen a Enodia la expulsión de excrementos por los epilépticos durante un ataque, mientras que a Hécate le atribuyen el envío de terrores nocturnos y los delirios.

12. Para imaginarnos el efecto del contenido de esta "mortífera cratera" podemos recurrir a otro pasaje de Eurípides, donde utiliza el participio de un verbo que pertenece a la familia de palabras de $\delta v \sigma \theta \alpha v \alpha \tau \alpha ́ \omega, \delta v \sigma \theta v \eta ̣ \sigma \kappa \omega$, verbo que significa

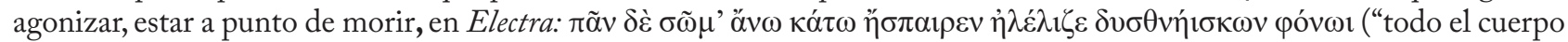
se convulsionó de arriba abajo y daba alaridos mientras moría de mala muerte", 842-843).

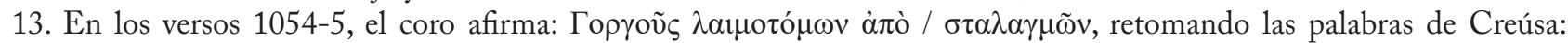

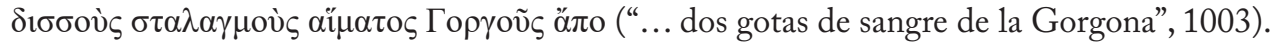


privado, sino a la dinastía gobernante. Esta petición obedece al deseo de proteger la pureza del linaje

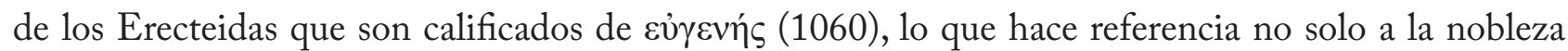
sino especialmente al nacimiento autóctono. Loraux (2017, p. 283) sostiene que noble y autóctono en

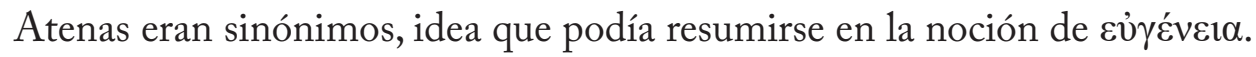

En relación con el tema de la posible usurpación del poder, Martin (2019 ad loc) señala que

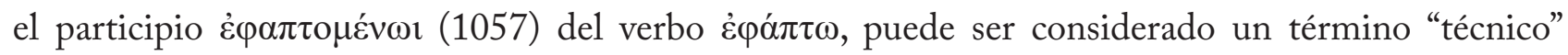
utilizado en contextos "legales" cuando se refiere a la confiscación de propiedad extranjera. ${ }^{14} \mathrm{La}$ supuesta intención de Juto e Ion de usurpar el poder al linaje de los Erecteidas justifica una "plegaria por la justicia”, buscando impedir estas ambiciones ilegales.

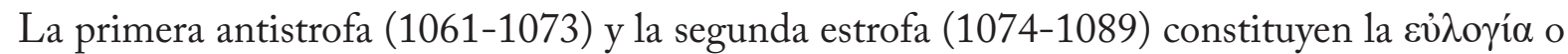
la "Begründung". La antistrofa describe lo que sucedería si Enodia-Hécate no escuchase la petición. Para las servidoras atenienses, lo que está en juego es la vida de Creúsa, ya que, si el plan fracasa, la reina se suicidará (1061-1073).

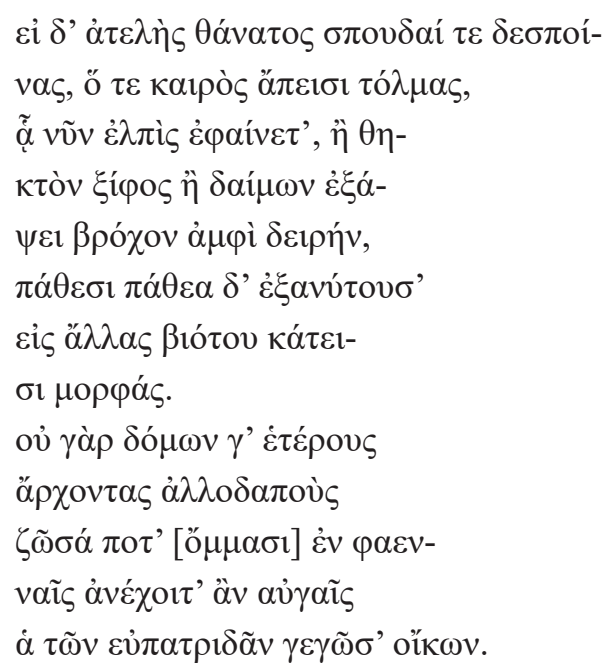

Y si la muerte y los esfuerzos de mi señora quedan inclumplidos, y está ausente el momento oportuno de audacia donde aparecía la esperanza, colocará su afilada espada o un nudo corredizo alrededor de su cuello, y venciendo sufrimientos con más sufrimientos descenderá a otras formas de vida. Pues viva, no resistiría ante sus ojos brillantes a otros gobernantes extranjeros en su casa, la que ha nacido en casa noble.

Creúsa se quitará la vida no por temor a ser castigada por intentar de envenenar a Ion, ${ }^{15}$ sino para evitar el dolor (1066) de ver a un usurpador extranjero, ocupando el trono de Atenas, y que este sea un

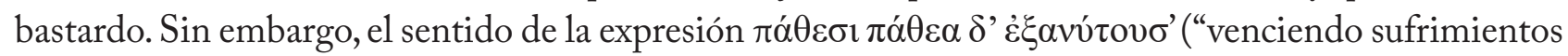
con más sufrimientos”, 1066), debe entenderse en un sentido más amplio. El descubrimiento de que Ion es hijo bastardo de Juto y que ella no podrá tener un hijo, un heredero legítimo, es el broche final

14. Así, por ejemplo, en A. Suppl. 412, 728; S. OC 859; P1. Leg. 915C.

15. En Atenas el uso de filtros amorosos estaba condenado por ley; así, por ejemplo, consultar P1. $L g$. XI 933d, Dem. lix 122 y Ael. H.V.V 18. 
para una vida signada por el sufrimiento: la violación de Apolo, la exposición de su hijo, la traición de Juto y el fin del linaje de Erecteo. Es por estos motivos que la orgullosa y última descendiente de los

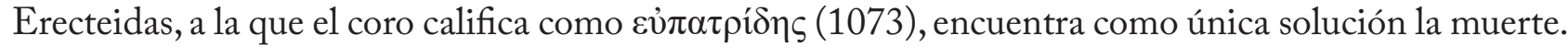

No obstante, la expresión del coro al hablar de la probable muerte de Creúsa sostiene que

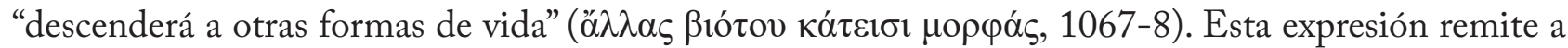
la creencia de que la existencia continúa en Hades. ${ }^{16}$ Esta idea no es una mera formulación literaria, ya que es validada por los hallazgos arqueológicos de artículos de uso diario como ofrendas fúnebres (véase Garland, 1985, p. 74-76). Asimismo, este verso puede leerse como una alusión a las creencias mistéricas, que serán explicitadas en la siguiente estrofa.

En la segunda estrofa (1074-1089), el coro detalla las consecuencias que el fracaso del plan de Creúsa acarreará a la ciudad hacia Atenas. Para reforzar lo pedido en el himno, las mujeres del coro expresan sus propios temores, es decir, imaginan las consecuencias que podría tener la intrusión de Ion en el centro ritual y político de Atenas como asistente de los Grandes Misterios (1074-86). La invocación inicial a Enodia-Hécate como hija de Deméter (1048) conecta las dos estrofas y motiva la elección de Eleusis como un culto que representa la identidad ateniense, dado que garantiza el bienestar de toda la ciudad. Este sentimiento del coro en el plano religioso también implica el rechazo del cuerpo ciudadano al extranjero Ion, ya que la comunidad ateniense cívica y religiosa es una en las celebraciones de las diosas elusinas y de Dioniso.

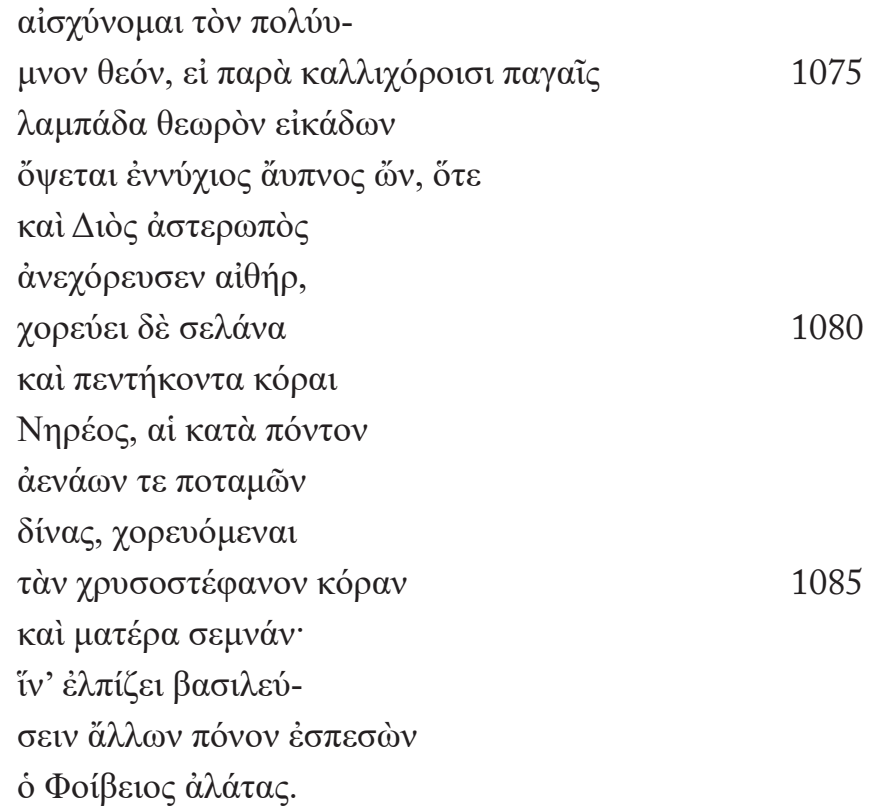

Siento vergüenza ante el dios de muchos himnos, si junto a las fuentes de bellos coros llega a ver como espectador en la noche y despierto la antorcha del día veinte, cuando hasta el éter estrellado de Zeus celebra con coros y danza la luna y las cincuenta hijas de Nereo, que en el ponto y en los remolinos de los ríos de perpetua corriente danzan celebrando a la Doncella de áurea corona de oro y su augusta Madre; allí espera reinar, cayendo sobre el trabajo de otros, ese intruso de Febo.

16. Esta idea también se encuentra en otras tragedias de Eurípides: Med. 1039, Hipp. 195 e IA 1507-8, entre otras. 
Puede verse así que la preocupación del coro se dirige a otro problema: las coreutas sienten vergüenza ( $\alpha i \sigma \chi v ́ v o \mu \alpha l, 1074)$ ante los dioses porque la sacralidad y la pureza de los misterios de Eleusis corren peligro de ser profanadas si Ion se convirtiera en espectador $(\theta \varepsilon \omega \rho o ́ s, 1076)$ de la

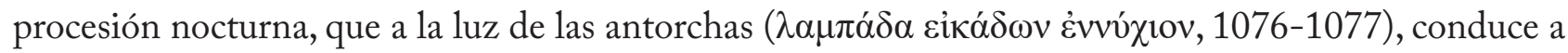
los atenienses al santuario de Eleusis, para realizar los ritos mistéricos. Es decir, Ion sería culpable de ver (1077) rituales que los no iniciados no podían ver (véase Semenzato, 2020, p. 847).

Aquí el himno menciona a un dios asociado a Enodia-Hécate, el dios de muchos himnos ( $\pi \circ \lambda$ v́uvov $\theta \varepsilon o ́ v, 1074-5$ ) es Dioniso, la deidad que actúa como nexo entre Atenas y Eleusis (cf. Craik, 1995, p. 1995). El epíteto $\pi 0 \lambda v ́ v \mu v o v$ es usualmente empleado para caracterizar al dios, ${ }^{17}$ quien es asimilado a Iaco, el dios de los misterios eleusinos, ${ }^{18}$ quien conducía a los iniciados el día veinte del mes Boedromión desde Atenas a Eleusis. El coro imagina al dios conduciendo coros en los que participan Selene y las Nereidas, a la luz de las antorchas, de noche, en honor de las Dos Diosas (1075-86; cf. Burian, 2009, ad loc, Clinton, 2007, p. 348). ${ }^{19}$ Gracias a esta danza coral el cosmos está unido: los humanos que celebran a las diosas de los misterios se unen con coros del aire y el mar (1078-86). La escena puede describir una experiencia mística: las delicias que gozan los iniciados se manifiestan en todo su entorno (la montaña y las bestias, véase E. IT 1242-3, Ba. 114, 726-7); además Iaco-Dioniso es el corego de las estrellas que danzan junto a los coros humanos (S. Ant.1146-52).

El coro también proporciona referencias topográficas, pues menciona "las fuentes de bellos

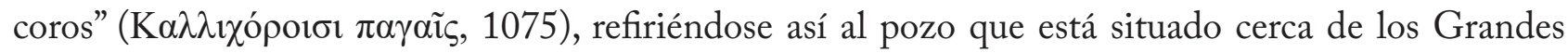
Propileos de Eleusis (véase h. Cer. 2.272, Paus. 1.38.6). No obstante más allá de la localización del ámbito donde tenían lugar los ritos sagrados, es importante subrayar que la referencia a las ejecuciones

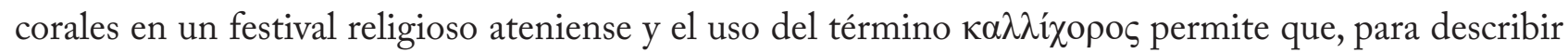
la actuación de las servidoras de Creúsa, hablemos de "proyección coral y autorreferencia coral", es decir, al hacer referencia a su propia danza en la ficción dramática el coro remite a su identidad extra-dramática como intérprete en la danza ritual (Henrichs, 1995). Esta autorreferencialidad se

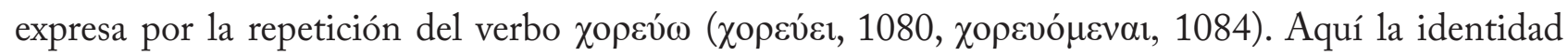
del coro muestra su doble faz, como personaje dramático, es decir, mujeres atenienses al servicio de la reina, como ciudadanos atenienses ejecutando un ritual en el festival cívico-religioso de las Grandes Dionisias. Sin embargo, como señala Rehm (2020, p. 836), debemos señalar que la proyección coral siempre tiene una "función dramática" en la tragedia. Las atenienses servidoras de Creúsa en este himno recuerdan pasadas participaciones en los Misterios Eleusinos, los que simbolizan la religión y las instituciones de la ciudad de Atenas, no solo para las doncellas de Creúsa, sino probablemente también para toda la audiencia de las Dionisias Ciudadanas (Semenzato, 2020, p. 847).

Al final de la estrofa, el coro menciona a las divinidades que presiden el festival, utilizando

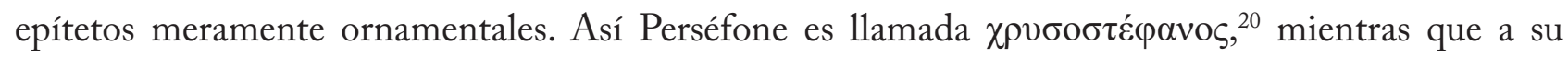
madre la denominan con uno de sus epítetos característicos, $\sigma \varepsilon \mu \nu \alpha ́$ (1085-6).

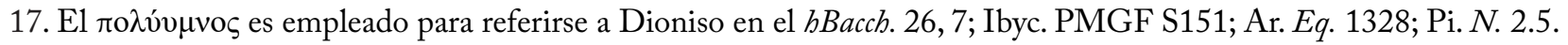

18. Véase, por ejemplo, E. Ba. 725-6; S. Ant. 1146-52; Fr. 959, schol. Vet. Ar. Ran. 403 b.

19. Cf. S. Ant. 1115 ss., A. Ra. 323-342.

20. En realidad, es un epíteto usual de Afrodita, por ej., bVen. 6.1; Saph. Fr. 33. 
Luego de la alegría de la celebración mistérica, el coro vuelve al aquí y ahora, refiriéndose a la participación de Ion en el ritual (1087-8) y en la vida cívica, comparándolo, según las palabras de Martin (2019 ad loc), con el comportamiento parasitario de los zánganos. El estásimo finaliza con otra referencia a la actividad coral (1090-1105) y asume una defensa "genérica" de su señora.

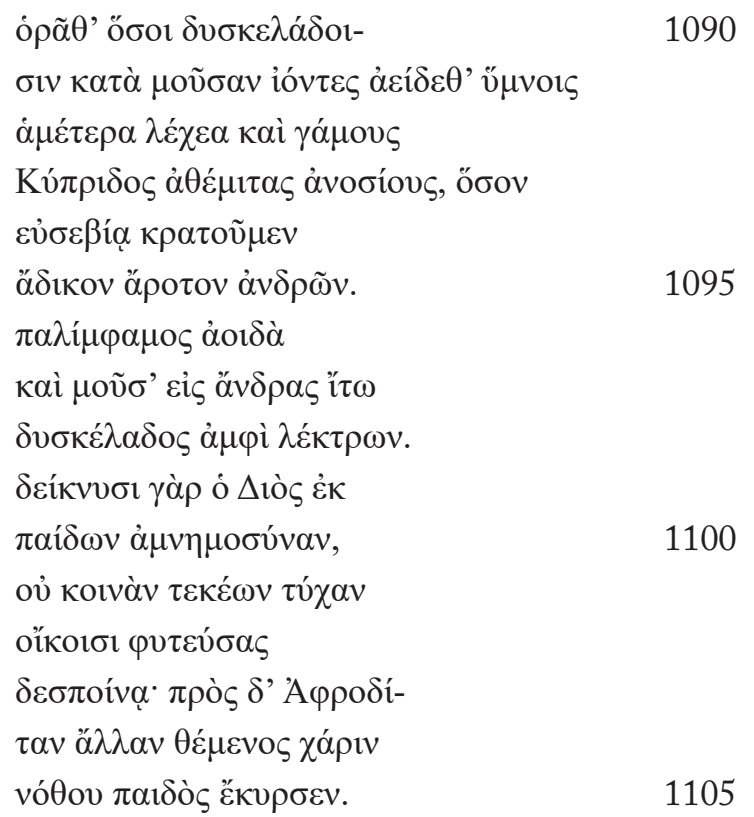

¡Contemplad cuántos con himnos maldicientes, viniendo contra la Musa, cantáis nuestros lechos y uniones de amor como impías e ilícitas! ¡Ved cómo superamos en piedad a la injusta progenie de los varones! Que un canto de rectificación, que vuestra Musa discordante llegue contra los hombres por sus lechos nupciales. Pues el hijo de los hijos de Zeus muestra olvido, cuando siembra para su casa una suerte de hijos no comunes con nuestra señora y, colocando el goce en otra Afrodita, ha conseguido un bastardo.

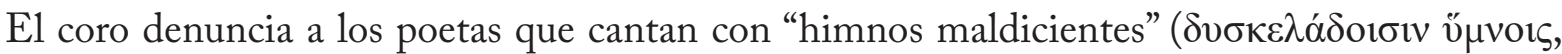
1090-1) sobre los supuestamente culpables amoríos femeninos. Así los poetas masculinos censuran las relaciones clandestinas femeninas mientras que silencian las masculinas. A partir del v. 1095, cuando el coro emplea la primera persona del plural, es cuando claramente vemos a las atenienses del séquito de Creúsa asumir y defender la posición de las mujeres en general, especialmente las de las deshonradas por una falaz mala reputación. Se describe el adulterio con el lenguaje de la contaminación y la mala

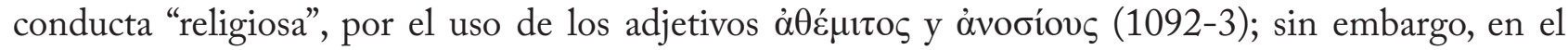
mundo antiguo, el adulterio es condenado porque daña los matrimonios legítimos, los que aseguran herederos legítimos, ya que pone en peligro el orden público.

En este himno que termina con una imprecación, el coro exhorta a los poetas a entonar un

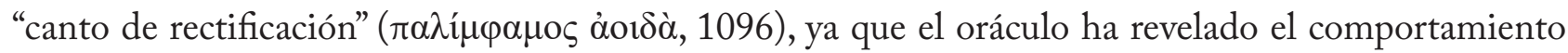
supuestamente injusto de Juto. Es decir, este coro de mujeres acusa al esposo de Creúsa, ya que consideran que Ion es fruto de los culpables amoríos del rey con una delfia. Es Juto quien se habría comportado de manera impía y sacrílega (ver vv. 1092-3). Sin embargo, estos versos bien podrían estar refiriéndose a Apolo, aunque las atenienses no lo saben. 


\section{Función del himno}

Podemos sostener que, dentro de la ficción dramática, este himno desempeña una doble función. Por un lado, puede ser pensado como una defixio, una maldición contra el posible usurpador del trono de Atenas. La maldición buscaría no solo colaborar mágicamente con los propósitos de su señora, sino defender la "pureza" del linaje real. A las mujeres del coro les resulta inconcebible que alguien que no

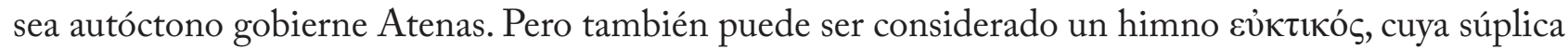
remite a la preocupación de las coreutas por la casa de Erecteo, para que un bastado no usurpe el trono, poniendo en entredicho la legitimidad real, y que no profane los misterios eleusinos, que constituían un elemento esencial de la religión ateniense.

Como señala Calame (2017, p. 64), el himno comenta y enriquece emocionalmente la acción dramática mientras busca, por medio de las formas ritualizadas, influenciar sobre el desarrollo de la acción. Las atenienses invocan a Enodia, protectora de los partos y de los niños recién nacidos, remitiendo a la supuesta realidad de Creúsa, a su carencia de hijos. Como se ha señalado al inicio de este trabajo, se han encontrado inscripciones de principios del siglo $\mathrm{V}$ en Larisa, solicitando ayuda para un niño. Como las dedicatorias son breves es difícil discernir si se pedía a Enodia que propiciase la concepción, o que ayudase en el parto, o que protegiese al niño recién nacido. ${ }^{21}$ En este caso, lo que se solicita es que Creúsa pueda concebir un hijo, pero probablemente el coro también quisiese propiciar un buen parto y una saludable crianza del futuro rey de Atenas.

Fuera de la ficción dramática, Enodia-Hécate o Enodia-Perséfone remite a los misterios eleusinos. Cabe señalar que Hécate desempeñaba un importante rol en dichos misterios, como compañera o asistente de Perséfone, ${ }^{22}$ especialmente en sus periódicos viajes al Hades. Esta función presenta a Hécate como moradora del Hades, reino de la oscuridad en el que la diosa se guía iluminándose por antorchas. Para los iniciados en los misterios es portadora de la luz en las tinieblas y de la luz de la revelación. Así, al invocar a Enodia-Hécate, como hija de Deméter, el coro puede estar refiriéndose al sincretismo con Perséfone. Esta posibilidad es evidente porque una de las preocupaciones de las coreutas era que se mantenga la santidad de Eleusis. ${ }^{23}$

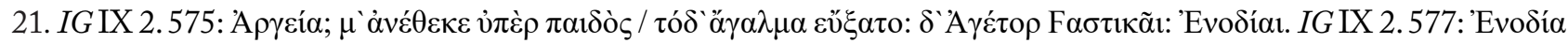

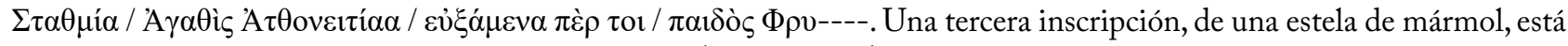

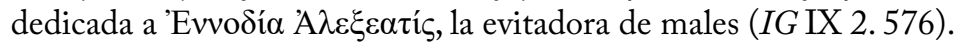

22. Cf. hCer. vv. 53-9, 438-40.

23. Cabe señalar que Hécate no solo está vinculada a los misterios de Eleusis sino que también existen testimonios sobre el culto mistérico que esta diosa recibía en Egina. Si bien son fuentes tardías las que plantean la relación de Hécate con los misterios, es posible pensar que estos ritos hayan tenido su origen en el período arcaico. Pausanias $(2,30.1)$ relaciona los misterios de la diosa con Orfeo: "De los dioses, los eginetas veneran sobre todo a Hécate, y todos los años celebran unos misterios de ella, diciendo que Orfeo el tracio los fundó para ellos”. Cf. Polinskays, 2013, p. 290 y ss. 


\section{Conclusión}

Dentro de la ficción dramática, el himno funciona como una suerte de defixio que busca perjudicar

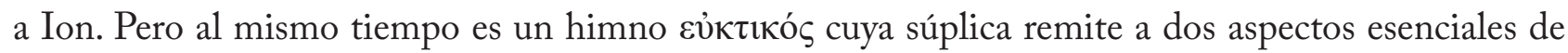
la tragedia: la descendencia y la sacralidad de Atenas. Por un lado, siendo Enodia protectora de los partos y de los niños recién nacidos, la petición del coro remite a la supuesta realidad de Creúsa, a su imposibilidad de tener hijos y la amenaza que implica el bastardo de Juto, quien podría usurpar el trono de Atenas. Por otro lado, Enodia, como hija de Deméter, remite a los misterios eleusinos, cuyos ritos son descritos. La aceptación del bastardo Ion no solo socava la legitimidad política de Atenas, sino que también pone en peligro su sistema religioso.

\section{Referencias bibliográficas}

Allan, W. (2004). Religious Syncretism: The New Gods of Greek Tragedy. Harvard Studies in Classical Philology, 102, 113-155.

Calame, Cl. (2017). La Tragédie Chorale: Poésie Grecque et Rituel Musical. Paris, Les Belles Lettres.

Clinton, K. (2007). The Mysteries of Demeter and Kore. En Ogden, D. (ed.), A Companion to Greek Religion (pp. 342-356). Oxford, Blackwell Publishing.

Craik, E. M. (1995). Euripides: Ion and Phoenissae. En Ayres, L. y Kidd, I. G., The Passionate Intellect: Essays on the Transformation of Classical Traditions (pp. 105-144), New Jersey, New Brunswick.

Di Piero, W. S. y Burian, P. (1996). Euripide. Ion. Oxford, Oxford University Press.

Faraone, Ch. A. y Obbink, D. (eds.) (1991). Magika Hiera. Ancient Greek Magic E Religion. New York/ Oxford, Oxford University Press.

Faraone, Ch. A. (1991). The Agonistic Context of Early Greek Binding Spells. En Faraone, Ch. A. y Obbink, D. (eds.), Magika Hiera. Ancient Greek Magic E Religion (pp. 3-32), New York/Oxford, Oxford University Press.

Furley, W. D. y Bremer, I. (2001). Greek Hymns (Vol. 1: The Texts in Translation. Vol. 2: Greek Texts and Commentary). Tübingen, Mohr Siebeck.

Gager, J. G. (1992). Curse Tablets and Binding Spells from the Ancient World. New York/Oxford, Oxford University Press.

Garland, R. (1988). The Greek Way of Death. Ithaca/New York, Cornell University Press.

Johnston, S. I. (1999). Hecate and the Dying Maiden. How the Mistress of Ghost Earned Her Title. En Restless dead: encounters between the living and the dead in ancient Greece (pp. 203-249). Berkeley/ London, University California Press.

Kyriakou, P. y Rengakos, A. (2016). Wisdom and Folly in Euripides. Berlin/Boston, Walter de Gruyter.

Loraux, N. (2017). Los hijos de Atenea. Barcelona, Acantilado. (Original de 1981.) 
Mantziou, M. (1981). Hymns and Hymnal Prayers in Fifth Century. Greek Tragedy with Special Reference to Euripides. London, Department of Greek, University of London.

Markantonatos, A. (2016). The Delphic School of Government: Apollonian Wisdom and Athenian Folly in Euripides' Ion. En Kyriakou, P. y Rengakos, A., Wisdom and Folly in Euripides (pp. 209228), Berlin/Boston, De Gruyter.

Markantonatos, A. (ed.) (2020). Brill's Companion to Euripides (Vol. 1 y 2). Leiden/Boston/Köln, Brill.

Martin, G. (2010). On The Date of Euripides' Ion. CQ, 60 (2), 647-651.

Martin, G. (2018). Euripides. Ion. Edition and Commentary. Berlin/Boston, De Gruyter.

Mikalson J. D. (1989). Unanswered Prayers in Greek Tragedy. JHS, 109, 81-98.

Mirecki, P. y Meyer, M. (eds.) (2002). Magical Ritual in the Ancient World. Leiden/Boston/Köln, Brill.

Mili, M. (2015). Religion and Society in Ancient Thessaly. Oxford, Oxford University Press.

Polinskays, I. (2013). A Local History of Greek Polytheism: Gods, People and the Land of Aegina, 800-400 $B C C$. Leiden/Boston, Brill.

Rehm, R. (2020). Ritual in Euripides. En Markantonatos, A. (ed.), Brill's Companion to Euripides (pp. 821-840), Leiden/Boston/Köln, Brill.

Semenzato, C. (2020). Euripides and Mystical Religion. En Markantonatos, A. (ed.), Brill's Companion to Euripides (pp. 841-862). Leiden/Boston, Brill.

Serafini, N. (2015). La dea Ecate e i luoghi di passaggio. Una protettrice dalla quale proteggersi. Kernos, 28, 111-131.

Versnel, H. S. (1991). Beyond Cursing: The Appeal to Justice in Judicial Prayers. En Faraone, Ch. A. y Obbink, D. (eds.), Magika Hiera. Ancient Greek Magic E Religion (pp. 60-106). New York/Oxford, Oxford University Press.

Versnel, H. S. (2002). The Poetics of the Magical Charm. An Essay in the Power of Words. En Mirecki, P. y Meyer, M. (eds.), Magical Ritual in the Ancient World (pp. 105-158). Leiden/Boston/ Köln, Brill.

Zografou, A. (2010). Chemis d' Hécate. Portes, routes, carrefours et autres figures de l'entre-deux. Belgique, Kernos Liège. 
*Marcela Alejandra Ristorto es Doctora en Letras, Profesora asociada de la cátedra Literatura Europea I de la Facultad de Humanidades y Artes de la Universidad Nacional de Rosario. Ha publicado artículos en revistas y volúmenes nacionales e internacionales. Su área de investigación actualmente se centra en la religión griega, en particular, en la himnodia (los himnos homéricos, los himnos trágicos y los himnos en los Papiros Mágicos). Directora del Centro de Estudios Helénicos y de Tradición Clásica de la UNR.

**Silvia Susana Reyes es Licenciada en Comunicación Social y Traductora matriculada. Docente de Lengua Griega II, miembro del Centro de Estudios Helénicos y de Tradición Clásica, miembro del Centro de Estudios sobre Tecnología Educativa y Herramientas Informáticas de Procesamiento del Lenguaje, y maestranda en Teoría Lingüística y Adquisición del Lenguaje (Facultad de Humanidades y Artes de la Universidad Nacional de Rosario).

RECIBIDO: 28/02/2021

ACEPTADO: 04/05/2021 